\title{
SEMI RING POLINOM ATAS ALJABAR MAX-PLUS
}

\author{
Suroto \\ Prodi Matematika, Jurusan MIPA, Fakultas Sains dan Teknik \\ Universitas Jenderal Soedirman \\ e-mail : suroto_80@yahoo.com
}

\begin{abstract}
In this paper we define polynomials over a max plus algebra. Furthermore we prove that the set of such polynomials is a semi ring.
\end{abstract}

Key words: semi ring, max-plus algebra, polynomial

ABSTRAK. Pada makalah ini didefinisikan polinom atas aljabar max-plus. Lebih lanjut dibuktikan bahwa himpunan semua polinom tersebut merupakan semi ring.

Kata kunci: semi ring, aljabar max-plus, polinom

\section{PENDAHULUAN}

Misalkan $S$ adalah suatu himpunan tidak kosong. Himpunan $S$ yang dilengkapi dengan suatu operasi biner yang bersifat assosiatif dinamakan semi grup (Fraelligh, 2000). Menurut Golan (2005), himpunan $S$ yang dilengkapi dengan dua buah operasi biner yakni penjumlahan (dinotasikan + ) dan pergandaan (dinotasikan $\times$ ) dinamakan semi ring apabila memenuhi:

1. $(S,+)$ merupakan semi grup komutatif dengan elemen netral.

2. $(S, \times)$ merupakan semi grup dengan elemen satuan.

3. Elemen netral merupakan elemen penyerap terhadap operasi $\times$.

4. Operasi + distributif terhadap operasi $\times$.

Semi ring $S$ dikatakan idempoten apabila untuk setiap $a \in S$ berlaku $a+a=a$ dan dikatakan komutatif apabila operasi pergandaannya bersifat komutatif (Mora, dkk, 2009). Suatu semi ring komutatif yang setiap elemen tak netralnya mempunyai invers terhadap operasi pergandaan dinamakan semi lapangan.

Misalkan diberikan struktur aljabar $\mathbb{R}_{\max } \stackrel{\text { def }}{=} \mathbb{R} \cup\{-\infty\}$ dengan $\mathbb{R}$ adalah himpunan semua bilangan riil, yang dilengkapi dengan dua buah operasi biner yakni operasi penjumlahan dan pergandaan. Aljabar max-plus merupakan struktur aljabar 
yang terbentuk dari $\mathbb{R}_{\max }$ dengan dilengkapi operasi "maximum" sebagai operasi penjumlahannya dan operasi "plus" sebagai operasi pergandaannya, yakni

$$
a \oplus b=\operatorname{maximum}(a, b) \text { dan } a \otimes b=a+b
$$

untuk setiap $a, b \in \mathbb{R}_{\max }$ (Farlow, 2009). Elemen identitas terhadap operasi penjumlahannya adalah $-\infty$ dan terhadap operasi pergandaannya adalah 0 . Himpunan $\mathbb{R}_{\max }$ yang dilengkapi dengan operasi penjumlahan dan pergandaan tersebut merupakan semi ring, dan selanjutnya dinamakan semi ring max-plus (Akian, dkk., 2006). Menurut Bacelli, dkk (2001), semi ring max-plus tersebut juga merupakan semi lapangan idempoten.

Pembahasan aljabar max-plus bisa diperluas pada kajian matriks yang dilakukan dengan cara mendefinisikan matriks dengan entri-entrinya adalah elemen pada aljabar max-plus. Kajian mengenai matriks atas aljabar max plus telah dilakukan oleh Rudhito, dkk (2008) dan diperoleh bahwa matriks atas aljabar maxplus terhadap operasi penjumlahannya merupakan semi grup komutatif idempoten, sedangkan terhadap operasi pergandaannya merupakan semi grup.

Telah diketahui sebelumnya bahwa aljabar max-plus merupakan semi lapangan idempoten. Pada makalah ini, pembahasan aljabar max-plus diperluas pada kajian polinom dengan cara membentuk polinom yang koefisiennya adalah elemenelemen pada aljabar max-plus. Selanjutnya, struktur aljabar max-plus dan sifatsifatnya sebagai semi lapangan akan digunakan untuk membuktikan beberapa sifat yang berkaitan dengan polinom yang dibentuk dari aljabar max-plus tersebut.

\section{SEMIRING POLINOM ATAS ALJABAR MAX-PLUS}

Bagian ini merupakan bagian utama pada penulisan makalah ini. Terlebih dahulu didefinisikan polinomial dengan setiap koefisiennya adalah elemen-elemen pada aljabar max-plus, seperti dinyatakan pada definisi berikut:

Definisi 2.1 Misalkan $\mathbb{R}_{\max }$ adalah aljabar max-plus maka polinom yang berbentuk

$$
f(x)=\sum_{i=0}^{n} a_{i} x^{i}=a_{0}+a_{1} x+\cdots+a_{n} x^{n}
$$


dengan $a_{0}, a_{1}, a_{2}, \ldots, a_{n} \in \mathbb{R}_{\max }$ dinamakan polinom atas aljabar max-plus dengan indeterminate $x$.

Untuk selanjutnya, himpunan semua polinom atas aljabar max-plus dinotasikan dengan $\mathbb{R}_{\max }[x]$, yakni

$$
\mathbb{R}_{\max }[\mathrm{x}]=\left\{a_{0}+a_{1} x+\cdots+a_{n} x^{n} \mid a_{0}, a_{1}, \ldots, a_{n} \in \mathbb{R}_{\max }\right\}
$$

Dua buah polinom di $\mathbb{R}_{\max }[\mathrm{x}]$ dikatakan sama apabila untuk setiap koefisien yang letaknya bersesuaian nilainya sama, yaitu

$$
a_{0}+a_{1} x+\cdots+a_{n} x^{n}=b_{0}+b_{1} x+\cdots+b_{m} x^{m}
$$

jika $a_{i}=b_{i}$ untuk setiap $i \geq 0$.

Definisi 2.2 Untuk setiap $a_{0}+a_{1} x+\cdots+a_{n} x^{n}, b_{0}+b_{1} x+\cdots+b_{m} x^{m} d i \mathbb{R}_{\max }[\mathrm{x}]$ , didefinisikan operasi penjumlahan polinom seperti berikut:

$$
\left(a_{0}+a_{1} x+\cdots+a_{n} x^{n}\right)+\left(b_{0}+b_{1} x+\cdots+b_{m} x^{m}\right)=c_{0}+c_{1} x+\cdots+c_{k} x^{k}
$$

dengan $c_{i}=a_{i} \oplus b_{i}=\max \left(a_{i}, b_{i}\right)$ untuk setiap $i$

Terlebih dahulu ditunjukkan bahwa operasi penjumlahan pada persamaan (2.1) terdefinisi dengan baik (well defined) di $\mathbb{R}_{\max }[\mathrm{x}]$. Misalkan polinomial $a_{0}+a_{1} x+$ $\cdots+a_{n} x^{n}, \quad b_{0}+b_{1} x+\cdots+b_{m} x^{m}, g_{0}+g_{1} x+\cdots+g_{k} x^{k}, h_{0}+h_{1} x+\cdots+h_{l} x^{l}$ di $\mathbb{R}_{\max }[\mathrm{x}]$. Jika

$$
\begin{gathered}
a_{0}+a_{1} x+\cdots+a_{n} x^{n}=b_{0}+b_{1} x+\cdots+b_{m} x^{m} \\
g_{0}+g_{1} x+\cdots+g_{k} x^{k}=h_{0}+h_{1} x+\cdots+h_{l} x^{l} \\
\operatorname{maka}\left(a_{0}+a_{1} x+\cdots+a_{n} x^{n}\right)+\left(g_{0}+g_{1} x+\cdots+g_{k} x^{k}\right) \\
=\left(a_{0} \oplus g_{0}\right)+\left(a_{1} \oplus g_{1}\right) x+\cdots+\left(a_{r} \oplus g_{r}\right) x^{r} \\
=\left(b_{0} \oplus h_{0}\right)+\left(b_{1} \oplus h_{1}\right) x+\cdots+\left(b_{r} \oplus h_{r}\right) x^{r} \\
=\left(b_{0}+b_{1} x+\cdots+b_{m} x^{m}\right)+\left(h_{0}+h_{1} x+\cdots+h_{l} x^{l}\right) .
\end{gathered}
$$


Dengan demikian, operasi penjumlahan pada $\mathbb{R}_{\max }[\mathrm{x}]$ terdefinisi dengan baik (well defined).

Definisi 2.3 Untuk setiap $a_{0}+a_{1} x+\cdots+a_{n} x^{n}, \quad b_{0}+b_{1} x+\cdots+b_{m} x^{m} d i$ $\mathbb{R}_{\max }[\mathrm{x}]$, didefinisikan operasi penjumlahan polinom seperti berikut:

$\left(a_{0}+a_{1} x+\cdots+a_{n} x^{n}\right) \times\left(b_{0}+b_{1} x+\cdots+b_{m} x^{m}\right)=d_{0}+d_{1} x+\cdots+d_{m+n} x^{m+n}$

dengan $d_{i}=\sum_{k=0}^{i} a_{k} b_{i-k}=\left(a_{0} \otimes b_{i}\right) \oplus\left(a_{1} \otimes b_{i-1}\right) \oplus \ldots \oplus\left(a_{i-1} \otimes b_{1}\right) \oplus$ $\left(a_{i} \otimes b_{0}\right)$

$$
=\max \left(\left(a_{0}+b_{i}\right),\left(a_{1}+b_{i-1}\right), \ldots,\left(a_{i-1}+b_{1}\right),\left(a_{i}+b_{0}\right)\right)
$$

Secara analog dengan operasi penjumlahan pada $\mathbb{R}_{\max }[\mathrm{x}]$, diperoleh bahwa operasi pergandaan pada $\mathbb{R}_{\max }[\mathrm{x}]$ juga terdefinisi dengan baik (well defined).

Sebelumnya sudah dijelaskan tentang pendefinisian operasi penjumlahan dan pergandaan pada $\mathbb{R}_{\max }[\mathrm{x}]$ yang terdefinisi dengan baik. Selanjutnya diperoleh bahwa $\mathbb{R}_{\text {max }}[\mathrm{x}]$ terhadap operasi penjumlahan pada persamaan (2.1) memenuhi aksiomaaksioma semigrup, seperti dinyatakan pada proposisi berikut:

Proposisi $2.1\left(\mathbb{R}_{\max }[\mathrm{x}],+\right)$ adalah semi grup komutatif dengan elemen netral.

Bukti. Untuk setiap $a_{0}+a_{1} x+\cdots+a_{n} x^{n}, b_{0}+b_{1} x+\cdots+b_{m} x^{m}, c_{0}+c_{1} x+$ $\cdots+c_{k} x^{k}$ polinom-polinom di $\mathbb{R}_{\max }[\mathrm{x}]$ berlaku :

i. $\left(a_{0}+a_{1} x+\cdots+a_{n} x^{n}\right)+\left(b_{0}+b_{1} x+\cdots+b_{m} x^{m}\right)=t_{0}+t_{1} x+\cdots+t_{k} x^{k}$

dengan $t_{i}=a_{i} \oplus b_{i}$, untuk setiap $i$. Karena $\mathbb{R}_{\max }$ adalah semi lapangan, maka berlaku $t_{i}=a_{i} \oplus b_{i}$ adalah elemen di $\mathbb{R}_{\max }$. Sehingga $t_{0}+t_{1} x+\cdots+t_{k} x^{k}$ merupakan polinom di $\mathbb{R}_{\max }[\mathrm{x}]$. Dengan demikian, operasi penjumlahan tertutup pada $\mathbb{R}_{\max }[\mathrm{x}]$. 
ii. $\left(\left(a_{0}+a_{1} x+\cdots+a_{n} x^{n}\right)+\left(b_{0}+b_{1} x+\cdots+b_{m} x^{m}\right)\right)+\left(c_{0}+c_{1} x+\cdots+\right.$ $\left.c_{k} x^{k}\right)$

$=p_{0}+p_{1} x+\cdots+p_{s} x^{s}$, dengan $p_{i}=\left(a_{i} \oplus b_{i}\right) \oplus c_{i}$ untuk setiap $i$. Karena $\mathbb{R}_{\max }$ adalah semi lapangan, maka berlaku $\left(a_{i} \oplus b_{i}\right) \oplus c_{i}=a_{i} \oplus\left(b_{i} \oplus c_{i}\right)$ untuk setiap $i$. Dari sini diperoleh bahwa

$$
\begin{aligned}
& \left(\left(a_{0}+a_{1} x+\cdots+a_{n} x^{n}\right)+\left(b_{0}+b_{1} x+\cdots+b_{m} x^{m}\right)\right)+\left(c_{0}+c_{1} x+\cdots+\right. \\
& \left.c_{k} x^{k}\right) \\
& =\left(a_{0}+a_{1} x+\cdots+a_{n} x^{n}\right)+\left(\left(b_{0}+b_{1} x+\cdots+b_{m} x^{m}\right)+\left(c_{0}+c_{1} x+\cdots+\right.\right. \\
& \left.\left.c_{k} x^{k}\right)\right) .
\end{aligned}
$$

Dengan demikian, operasi penjumlahan bersifat assosiatif di $\mathbb{R}_{\max }[\mathrm{x}]$.

iii. $\left(a_{0}+a_{1} x+\cdots+a_{n} x^{n}\right)+\left(b_{0}+b_{1} x+\cdots+b_{m} x^{m}\right)=t_{0}+t_{1} x+\cdots+t_{k} x^{k}$

dengan $t_{i}=a_{i} \oplus b_{i}$, untuk setiap $i$. Karena $\mathbb{R}_{\max }$ adalah semi lapangan, maka berlaku $a_{i} \oplus b_{i}=b_{i} \oplus a_{i}$ untuk setiap $i$. Dengan demikian diperoleh bahwa

$$
\begin{aligned}
& \left(a_{0}+a_{1} x+\cdots+a_{n} x^{n}\right)+\left(b_{0}+b_{1} x+\cdots+b_{m} x^{m}\right) \\
= & \left(b_{0}+b_{1} x+\cdots+b_{m} x^{m}\right)+\left(a_{0}+a_{1} x+\cdots+a_{n} x^{n}\right)
\end{aligned}
$$

sehingga operasi penjumlahan bersifat komutatif di $\mathbb{R}_{\max }[\mathrm{x}]$.

iv. Polinom netral didefinisikan sebagai polinom dengan semua koefisiennya adalah elemen netral pada $\mathbb{R}_{\max }$ yakni $-\infty$. Polinom netral ini mempunyai bentuk

$$
a_{0}+a_{1} x+\cdots+a_{n} x^{n}
$$

dengan $a_{i}=-\infty$, untuk setiap $i$. Polinomial ini merupakan elemen identitas di $\mathbb{R}_{\max }[\mathrm{x}]$ terhadap operasi penjumlahan. Dengan demikian, eksistensi elemen netral pada $\mathbb{R}_{\max }[\mathrm{x}]$ terpenuhi. Untuk selanjutnya, polinom netral cukup ditulis $0(x)$. 
Dari uraian di atas, terbukti bahwa $\mathbb{R}_{\max }[\mathrm{x}]$ terhadap operasi penjumlahan adalah semi grup komutatif dengan elemen netral.

Selain itu, diperoleh bahwa $\mathbb{R}_{\max }[\mathrm{x}]$ terhadap operasi pergandaan pada persamaan (2.2) juga memenuhi aksioma-aksioma semigrup, seperti dinyatakan pada proposisi berikut:

Proposisi $2.2\left(\mathbb{R}_{\max }[\mathrm{x}], \times\right)$ adalah semi grup dengan elemen satuan.

Bukti. Untuk setiap $a_{0}+a_{1} x+\cdots+a_{n} x^{n}, b_{0}+b_{1} x+\cdots+b_{m} x^{m}, c_{0}+c_{1} x+$ $\cdots+c_{r} x^{r}$ polinom-polinom di $\mathbb{R}_{\max }[\mathrm{x}]$ berlaku :

i. $\left(a_{0}+a_{1} x+\cdots+a_{n} x^{n}\right) \times\left(b_{0}+b_{1} x+\cdots+b_{m} x^{m}\right)=t_{0}+t_{1} x+\cdots+t_{k} x^{k}$

dengan $t_{i}=\sum_{k=0}^{i} a_{k} b_{i-k}$. Karena $\mathbb{R}_{\max }$ adalah semi lapangan, maka $t_{i}=$ $\sum_{k=0}^{i} a_{k} b_{i-k}$ adalah elemen pada $\mathbb{R}_{\max }$. Jadi $t_{0}+t_{1} x+\cdots+t_{k} x^{k}$ adalah polinom di $\mathbb{R}_{\max }[\mathrm{x}]$. Dengan demikian, operasi pergandaan tertutup di $\mathbb{R}_{\max }[\mathrm{x}]$.

ii. $\left(\left(a_{0}+a_{1} x+\cdots+a_{n} x^{n}\right) \times\left(b_{0}+b_{1} x+\cdots+b_{m} x^{m}\right)\right) \times\left(c_{0}+c_{1} x+\cdots+c_{k} x^{k}\right)$

$$
\begin{aligned}
& =\left(\left(\sum_{i=0}^{n} a_{i} x^{i}\right) \times\left(\sum_{i=0}^{m} b_{i} x^{m}\right)\right) \times\left(\sum_{i=0}^{k} c_{i} x^{k}\right) \\
& =\left[\sum_{j=0}^{n+m}\left(\sum_{j=0}^{i} a_{j} b_{i-j}\right) x^{i}\right] \times\left(\sum_{i=0}^{k} c_{i} x^{k}\right) \\
& =\sum_{i=0}^{n+m+k}\left[\sum_{j=0}^{i}\left(\sum_{p=0}^{j} a_{p} b_{j-p}\right) c_{j}\right] x^{i} \\
& =\sum_{i=0}^{n+m+k}\left(\sum_{j+p+l=i} a_{j} b_{p} c_{l}\right) x^{i} \\
& =\sum_{i=0}^{n+m+k}\left[\sum_{j=0}^{i} a_{j}\left(\sum_{p=0}^{i-j} b_{p} c_{i-j-p}\right)\right] x^{i} \\
& =\left(\sum_{i=0}^{n} a_{i} x^{i}\right) \times\left[\sum_{i=0}^{m+k}\left(\sum_{j=0}^{i} b_{j} c_{i-j}\right) x^{i}\right] \\
& =\left(\sum_{i=0}^{n} a_{i} x^{i}\right) \times\left(\left(\sum_{i=0}^{m} b_{i} x^{i}\right) \times\left(\sum_{i=0}^{k} c_{i} x^{i}\right)\right)
\end{aligned}
$$


$=\left(a_{0}+a_{1} x+\cdots+a_{n} x^{n}\right) \times\left(\left(b_{0}+b_{1} x+\cdots+b_{m} x^{m}\right) \times\left(c_{0}+c_{1} x+\cdots+c_{k} x^{k}\right)\right)$

Dengan demikian operasi pergandaan bersifat assosiatif di $\mathbb{R}_{\max }[\mathrm{x}]$

iii. Polinom satuan pada $\mathbb{R}_{\max }[\mathrm{x}]$ didefinisikan sebagai polinomial yang berbentuk

$$
a_{0}+a_{1} x+\cdots+a_{n} x^{n}
$$

dengan $a_{0}$ adalah elemen satuan di $\mathbb{R}_{\max }$ yakni 0 dan $a_{i}$ adalah elemen netral pada $\mathbb{R}_{\max }$ yakni $-\infty$ untuk setiap $i \neq 0$. Polinom ini merupakan elemen identitas di $\mathbb{R}_{\max }[\mathrm{x}]$ terhadap operasi pergandaan. Dengan demikian, eksistensi elemen satuan pada $\mathbb{R}_{\max }[\mathrm{x}]$ terpenuhi. Untuk selanjutnya, elemen satuan pada $\mathbb{R}_{\max }[\mathrm{x}]$ dinotasikan dengan $1(x)$.

Dari uraian tersebut di atas, terbukti bahwa $\mathbb{R}_{\max }[\mathrm{x}]$ dengan operasi pergandaan adalah semi grup dengan elemen satuan.

Selanjutnya dari hasil yang diperoleh pada Proposisi 2.1 dan Proposisi 2.2 dapat ditunjukkan bahwa $\mathbb{R}_{\max }[\mathrm{x}]$ terhadap operasi penjumlahan dan pergandaan pada persamaan (2.1) dan (2.2) adalah semi ring, seperti yang dinyatakan pada proposisi berikut yang merupakan hasil utama pada paper ini.

Proposisi $2.3\left(\mathbb{R}_{\max }[\mathrm{x}],+, \mathrm{X}\right)$ adalah semi ring.

Bukti. Sebelumnya sudah diketahui bahwa $\mathbb{R}_{\max }$ merupakan semi lapangan, sehingga elemen netral pada $\mathbb{R}_{\max }$ merupakan elemen penyerap terhadap operasi pergandaan, yakni

$$
a \otimes-\infty=-\infty \otimes a=-\infty
$$

untuk setiap $a \in \mathbb{R}_{\max }$. Karena $-\infty$ adalah elemen penyerap pada $\mathbb{R}_{\max }$, maka untuk setiap polinom $b_{0}+b_{1} x+\cdots+b_{n} x^{n}$ di $\mathbb{R}_{\max }[\mathrm{x}]$ berlaku

$$
0(x) \times\left(b_{0}+b_{1} x+\cdots+b_{n} x^{n}\right)=0(x) \times\left(b_{0}+b_{1} x+\cdots+b_{n} x^{n}\right)=0(x) .
$$


Dengan demikian, elemen netral pada $\mathbb{R}_{\max }[\mathrm{x}]$ yakni $0(x)$ merupakan elemen penyerap terhadap operasi pergandaan. Selanjutnya, untuk setiap polinom

$$
a_{0}+a_{1} x+\cdots+a_{n} x^{n}, b_{0}+b_{1} x+\cdots+b_{m} x^{m}, c_{0}+c_{1} x+\cdots+c_{r} x^{r}
$$

di $\mathbb{R}_{\max }[\mathrm{x}]$ berlaku

$$
\begin{aligned}
{\left[\left(a_{0}+a_{1} x+\cdots+a_{n} x^{n}\right)+\left(b_{0}+b_{1} x+\cdots+b_{m} x^{m}\right)\right] \times\left(c_{0}+c_{1} x+\cdots+c_{r} x^{r}\right) } \\
=\left(\left(\sum_{i=0}^{n} a_{i} x^{i}\right)+\left(\sum_{i=0}^{m} b_{i} x^{i}\right)\right) \times\left(\sum_{i=0}^{r} c_{i} x^{i}\right) \\
=\left(\sum_{i=0}^{k}\left(a_{i} \oplus b_{i}\right) x^{i}\right) \times\left(\sum_{i=0}^{r} c_{i} x^{i}\right) \\
=\left(\left(\sum_{i=0}^{n} a_{i} x^{i}\right) \times\left(\sum_{i=0}^{r} c_{i} x^{i}\right)\right)+\left(\left(\sum_{i=0}^{m} b_{i} x^{i}\right) \times\left(\sum_{i=0}^{r} c_{i} x^{i}\right)\right) \\
=\left[\left(a_{0}+a_{1} x+\cdots+a_{n} x^{n}\right) \times\left(c_{0}+c_{1} x+\cdots+c_{r} x^{r}\right)\right] \\
\quad+\left[\left(b_{0}+b_{1} x+\cdots+b_{n} x^{n}\right) \times\left(c_{0}+c_{1} x+\ldots+c_{r} x^{r}\right)\right]
\end{aligned}
$$

Secara analog diperoleh bahwa

$$
\begin{aligned}
\left(c_{0}+c_{1} x+\cdots+c_{r} x^{r}\right) \times\left[\left(a_{0}+a_{1} x+\cdots+a_{n} x^{n}\right)+\left(b_{0}+b_{1} x+\cdots+b_{m} x^{m}\right)\right] \\
=\left[\left(c_{0}+c_{1} x+\cdots+c_{r} x^{r}\right) \times\left(a_{0}+a_{1} x+\cdots+a_{n} x^{n}\right)\right] \\
\quad+\left[\left(c_{0}+c_{1} x+\cdots+c_{r} x^{r}\right) \times\left(b_{0}+b_{1} x+\cdots+b_{m} x^{m}\right)\right]
\end{aligned}
$$

Jadi operasi penjumlahan distributif terhadap operasi pergandaan.

Karena $\left(\mathbb{R}_{\max }[\mathrm{x}],+\right)$ adalah semi grup komutatif dengan elemen netral, $\left(\mathbb{R}_{\max }[\mathrm{x}], \mathrm{x}\right)$ adalah semi grup dengan elemen satuan, elemen netral pada $\mathbb{R}_{\max }[\mathrm{x}]$ merupakan elemen penyerap terhadap operasi pergandaan, dan operasi penjumlahan distributif terhadap operasi pergandaan, maka terbukti bahwa $\left(\mathbb{R}_{\max }[\mathrm{x}],+, \times\right)$ adalah semi ring.

Untuk selanjutnya, semi ring $\left(\mathbb{R}_{\max }[\mathrm{x}],+, \times\right)$ ini dinamakan semi ring polinomial atas aljabar max-plus. 


\section{KESIMPULAN}

Perluasan kajian aljabar max-plus dapat dilakukan pada kajian polinom yang dilakukan dengan cara mendefinisikan polinom dengan koefisiennya adalah elemenelemen pada aljabar max-plus. Polinom yang dibentuk ini selanjutnya dinamakan sebagai polinom atas aljabar max-plus. Himpunan semua polinom atas aljabar maxplus yang dilengkapi dengan operasi penjumlahan polinomial merupakan semi grup komutatif dengan elemen netral, sedangkan dengan operasi pergandaan polinomial merupakan semi grup dengan elemen satuan. Lebih lanjut, himpunan semua polinomial atas aljabar max-plus ini merupakan semi ring. Penelitian lanjut dapat dilakukan untuk semi modul atas semiring polinomial atas aljabar max-plus.

\section{DAFTAR PUSTAKA}

Akian, M., Bapat, R., and Gaubert, S. (2006). Max-Plus Algebra. Chapman and Hall Bacelli, F., Cohen, G., Olsder, G.J., and Quadrat, J.P. (2001). Synchronization and Linearity. An Algebra for Discrete Event Systems. John Wiley \& Sons. New York

Farlow, K.G. (2009). Max-Plus Algebra. Master's Thesis. Virginia Polytechnic Institute and State University

Fraleigh, J.B. (2000). A First Course in Abstract Algebra. Addison-Wesley Publising Company, Inc. New York

Golan, J.S. (2005). Some Recent Apllications of Semiring Theory. National Cheng Kung University, Tainan.

Mora, W., Wasanawichit, A., and Kemprasit, Y. (2009). Invertible Matrices over Idempotent Semirings. Chamchuri Journal of Mathematics, Vol 1 Number 2, $(55-61)$

Rudhito, A.M., Wahyuni, S. , Suparwanto, A., dan Susilo, F. (2008). Matriks atas Aljabar Max-Plus Interval. Jurnal Natur Indonesia 13(2), Februari 2011 (9499) 